\title{
FREQÜÊNCIA DE OCORRÊNCIA DE AGENTES ETIOLÓGICOS, SINTOMAS E ORIGEM DE AMOSTRAS DO CAFEEIRO CATALOGADOS EM 12 ANOS DE CLÍNICA FITOSSANITÁRIA DA UFLA
}

\author{
DANIEL GARCIA JÚNIOR \\ EDSON AMPÉLIO POZZA ${ }^{1}$ \\ PAULO ESTEVÃO DE SOUZA ${ }^{1}$ \\ VIVIANE TALAMINI ${ }^{3}$ \\ ADÉLIA AZIZ ALEXANDRE POZZA ${ }^{2}$ \\ HILÁRIO ANTÔNIO DE CASTRO ${ }^{1}$ \\ RICARDO MAGELA DE SOUZA ${ }^{1}$ \\ MÁRIO SOBRAL DE ABREU ${ }^{1}$ \\ LUDWIG HEINRICH PFENNING ${ }^{1}$
}

\begin{abstract}
RESUMO - Situada no sul de Minas Gerais, principal região cafeeira do País, a Clínica Fitossanitária da Universidade Federal de Lavras tem auxiliado os produtores, dando suporte na diagnose de doenças de origem biótica e abiótica, de modo a gerar subsídios para minimizar as perdas na produção. Nos últimos doze anos, foram analisadas 378 amostras de café. Em 78,6\% das amostras, foram detectados fungos, destacando-se $\mathrm{Col}$ -
\end{abstract}

letotrichum sp. (29\%), Rhizoctonia solani (18\%), Cercospora coffeicola (13\%), Phoma sp. (13\%) e Fusarium sp (11\%). Ocorreram ainda em números representativos casos de fitotoxidez, deficiência de nutrientes e problemas no sistema radicular. Devido à localização da Clínica, a maior parte das amostras foi proveniente de localidades na região sul do Estado (63\%), seguido do Triângulo Mineiro (12\%) e Zona da Mata (10\%).

TERMOS PARA INDEXAÇÃO: Doenças, cafeeiro, Clínica Fitossanitária e epidemiologia, Coffea arabica.

\section{ORIGIN OF COFFEE SAMPLES, FREQUENCY OF OCURRENCE OF ETHIOLOGICAL AGENTS AND SYMPTON IN TWELVE YEARS OF THE PLANT DISEASE CLINIC AT UFLA}

\begin{abstract}
The Phytossanitary Clinic of the Federal University of Lavras, situated in the south of the State of Minas Gerais has given support to coffee producers providing diagnoses of biotic and abiotic diseases, to generate subsidies to minimize losses in production of this crop. During the last twelve years, 378 samples have been analyzed. Fungi were detected in $78,6 \%$ of the samples. The major fungi found were
\end{abstract}

Colletotrichum sp. (29\%), Rhizoctonia solani (18\%), Cercospora coffeicola (13\%), Phoma sp. (13\%), e Fusarium sp (11\%). Other incidences were caused by phytotoxity, mineral deficiency and bad formation of the roots. Due to the location of the Phytossanitary Clinic, most of the samples came from locations of South of Minas Gerais (63\%), followed by Triângulo Mineiro (12\%) and Zona da Mata (10\%).

INDEX TERMS: Diseases, coffee, Plant Disease Clinic and epidemiology, Coffea arabica.

\footnotetext{
1. Professor do Departamento de Fitopatologia da UNIVERSIDADE FEDERAL DE LAVRAS/UFLA, Caixa Postal 37, 37200-000, Lavras, MG.

2. Estudante de pós-graduação do Departamento de Ciência do Solo da UFLA.

3. Estudante de pós-graduação do Departamento de Fitopatologia da UFLA.
} 


\section{INTRODUÇÃO}

De acordo com o Anuário Estatístico do Café (2000), o Brasil é o primeiro produtor de café verde do mundo. O País foi responsável por $23,1 \%$ da produção mundial. Vários fatores podem contribuir para reduzir essa produção e ameaçar a entrada de divisas no País. Uma das principais causas da redução na produtividade são as doenças. Podem ocorrer diversas doenças nessa cultura, desde o viveiro até o campo de produção, incluindo atualmente os problemas de armazenamento como as micotoxinas. Dependendo da região produtora, as doenças podem ser as principais responsáveis pela baixa produtividade (Zambolim et al., 1997). Tanto doenças bióticas quanto abióticas podem comprometer a produção e a produtividade, resultar em perdas e culminar em graves prejuízos para produtores e consumidores (Agrios, 1997). A magnitude das perdas é condicionada ao tipo de cultura, ao patógeno, à localidade, ao ambiente $\mathrm{e}$ às medidas de controle. Enfim, os produtos agrícolas podem sofrer perdas em quantidade e qualidade, em razão da simples ocorrência das doenças no campo, ou durante o armazenamento e transporte (Pozza, 1994).

A diagnose de doenças de plantas é o principal papel das Clínicas Fitossanitárias (CF). A diagnose correta de doenças pode auxiliar os cafeicultores e os extensionistas a evitarem o erro e a conseqüente recomendação inadequada de medidas de controle, principalmente no uso de defensivos agrícolas. Os arquivos das $\mathrm{CF}$ podem reunir informações valiosas sobre as dúvidas de maior freqüência dos extensionistas em relação à etiologia, sintomas ou patógenos de maior ocorrência. Em outros países, essas informações permitem avaliar a importância de doenças, associadas a diversos patógenos e regiões (Gomide, 1989; Pozza et al, 1999).

Diante disso, conduziu-se este trabalho com o objetivo de avaliar a freqüência dos agentes etiológicos, sintomas, gêneros de fungos e bactérias e respectivas regiões de onde foram recebidas as amostras diagnosticadas na Clínica Fitossanitária do Departamento de Fitopatologia da UFLA.

\section{MATERIAL E MÉTODOS}

Realizou-se levantamento da freqüência de ocorrência dos agentes etiológicos, sintomas, gêneros de fungos e bactérias e respectivas regiões de onde foram recebidas as amostras diagnosticadas. Esse levantamento foi realizado na Clínica Fitossanitária do Departamento de Fitopatologia da UFLA com base em dados catalogados em arquivo de janeiro de 1990 a Dezembro de 2001. Esse arquivo foi disponibilizado em banco de dados Access ${ }^{\circledR}$ (Microsoft Inc.).

Logo após o recebimento das plantas ou órgãos doentes, na Clínica, foi realizada triagem, de modo a separar doenças de natureza biótica e abiótica, por meio da análise dos sintomas, baseando na literatura básica como Barnett et al. (1987), Hawksworth et al. (1995), Ponte (1996), Kimati et al. (1997), Zambolin et al. (1997) e consultas ao herbário "Prof. Josué Augusto Deslandes", do Departamento de Fitopatologia da UFLA.

As amostras com doenças de natureza biótica foram submetidas à avaliação preliminar para identificar o agente etiológico (fungo, bactéria, vírus ou nematóide). Em seguida, foram encaminhadas aos laboratórios de pesquisa específicos, como bacteriologia, virologia, e aos laboratórios de controle de enfermidades fúngicas e de epidemiologia para identificar os fungos. As amostras suspeitas da ocorrência de nematóides foram encaminhadas ao laboratório de nematologia e não constam desse trabalho.

Para os fungos do cafeeiro, quando não foi possível identificar imediatamente, por sintomas e análise da morfologia dos mesmos, procedeu-se ao isolamento, em meio BDA (Batata-dextrose-ágar) e/ou ágar-água e/ou PCA (Potato-carrot-agar), segundo técnicas descritas por Kiraly (1974). No caso de dúvida sobre a relação patógeno-hospedeiro, foi realizado o postulado de Koch.

Nos materiais com suspeita de infecção por bactérias, os quais apresentavam sintomas de anasarca nos tecidos, principalmente nas folhas, foi realizado o teste de exsudação em gota (Romeiro, 1995). As amostras com resultado positivo foram submetidas ao isolamento em meio Kado \& Heskett (1970). Após o crescimento, foram observadas a pureza do isolamento, a cor, a morfologia das colônias e a pigmentação fluorescente. Para identificar Xylella fastidiosa, utilizou-se a técnica de PCR (Polimerase Chain Reaction). O vírus da manchaanular do cafeeiro foi identificado por sintomas e microscopia eletrônica de transmissão, quando necessário.

\section{RESULTADOS E DISCUSSÃO}

Entre janeiro de 1990 e dezembro de 2001, foram analisadas 378 amostras de café, recebidas na Clínica Fitossanitária da UFLA. Os fungos, com 78,6\%, foram o agente etiológico de maior frequiência, seguidos das bactérias, com 4,8\%, e deficiência de nutrientes e fitotoxidez, ambas com 4\% (Figura 1). 


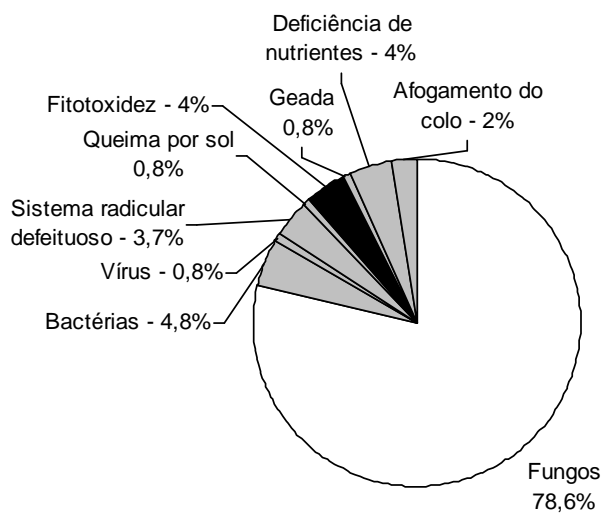

FIGURA 1 - Frequiência da ocorrência de agentes etiológicos bióticos e abióticos em amostras recebidas na Clínica Fitossanitária do DFP/UFLA, entre janeiro de 1990 e dezembro de 2001.

Os fungos, seguidos pelas bactérias, foram os agentes etiológicos de maior ocorrência, para doenças bióticas, concordando com os resultados descritos por Zambolin \& Ribeiro do Vale (1985) e Pozza et al. (1999). Esses autores afirmaram ser os fungos os principais responsáveis por doenças de plantas. $\mathrm{O}$ manejo inadequado da lavoura cafeeira, desde a formação das mudas até a colheita, mostrou-se significativo, destacando-se a deficiência de nutrientes, a fitotoxidez, a má formação do sistema radicular e o afogamento do colo da planta no plantio das mudas, totalizando $13,7 \%$ das amostras recebidas.

Colletotrichum sp (29\%) foi encontrado com maior frequiência nas amostras recebidas, seguido por Rhizoctonia solani (18\%), Phoma sp (13\%), Cercospora coffeicola (13\%) e Fusarium sp (11\%) (Figura 2). A maior incidência de Colletotrichum sp ocorreu pelo fato de essa doença estar associada a sintomas nos frutos, mancha manteigosa nas folhas e também seca de ponteiros. Todos esses sintomas geram dúvidas no campo em relação à etiologia da doença. Esse é o principal motivo para que os agentes de extensão encaminhem à Clínica Fitossanitária uma amostra, ou seja, a existência de dúvida quanto à diagnose correta. Os sintomas de mancha nos frutos também podem estar associados a Cercospora coffeicola. A seca dos ponteiros pode estar associada a vários outros patógenos e/ou à etiologia abiótica (Zambolin et al., 1997).

As espécies de Phoma sp e Fusarium sp foram identificadas por Salgado \& Pfenning (2000) e Pfenning $\&$ Martins (2000), respectivamente. As principais espécies de Phoma sp encontradas foram P. tarda e $P$. costarricensis. Entre as espécies de Fusarium sp, os autores acima identificaram $F$. oxysporum, $F$. solani, $F$. verticilloides, F. equiseti e F. stilboides.
Doenças de fácil diagnose no campo geralmente não foram encaminhadas para a Clínica, como é o caso da ferrugem, com somente $3 \%$ de ocorrência.

$R$. solani foi responsável pela segunda maior ocorrência. $\mathrm{O}$ fungo foi o agente etiológico do tombamento e da Rizoctoniose tardia no campo, geralmente associada ao afogamento do colo da planta. Esse último sintoma foi encontrado de forma significativa, principalmente em árvores com até 2 anos. Sintomas reflexos também foram observados, como amarelecimento, seca das folhas e nanismo das plantas, constituindo quadro sintomatológico típico.

Entre as bactérias, a de maior ocorrência foi $X$ ylella fastidiosa, constatada recentemente nos cafezais brasileiros. Pseudomonas cichorii apresentou sintomas nas folhas no viveiro, principalmente em mudas nos tubetes, durante os meses de novembro a março. $\mathrm{O}$ fato deve-se a irrigações constantes realizadas nesse tipo de viveiro. O tubete possui pouca quantidade de substrato e, portanto, exige várias irrigações diárias por aspersão. A água de irrigação favorece a disseminação e a penetração da bactéria (Romeiro, 1995).

Recentemente, também o vírus da mancha anular do cafeeiro foi detectado em amostras recebidas na Clínica Fitossanitária. O sintoma, quando no início, assemelha-se a pústulas jovens da ferrugem.

Os sintomas de maior ocorrência foram as manchas foliares $(42,3 \%)$, manchas nos frutos $(20,2 \%)$, amarelecimento $(12,5 \%)$, murcha seguida de seca $(8 \%)$ e tombamento de mudas no viveiro $(7,1 \%)$. As manchas foliares também foram o sintoma de maior ocorrência encontrados por Pozza (1999) e também no herbário Prof. Josué Augusto Deslandes do DFP/UFLA. O amarelecimento estava associado geralmente à murcha seca 
de ponteiros e nanismo. As principais etiologias desse quadro sintomatológico foram deficiências nutricionais, problemas na raiz, afogamento do colo, falta de água no viveiro ou campo, Xylella fastitiosa e o vírus da mancha anular. Esse último também estava associado a descolorações nos frutos.
A maioria das amostras foram originárias do sul de Minas Gerais (63\%), Triângulo Mineiro (12\%) e Zona da Mata de Minas (10\%) (Figura 3). O fato de o sul de Minas ser a região de maior demanda se deve à maior proximidade com a UFLA e também por ser a maior região produtora de café do Brasil, além de receber maior divulgação sobre os serviços prestados pela Clínica.

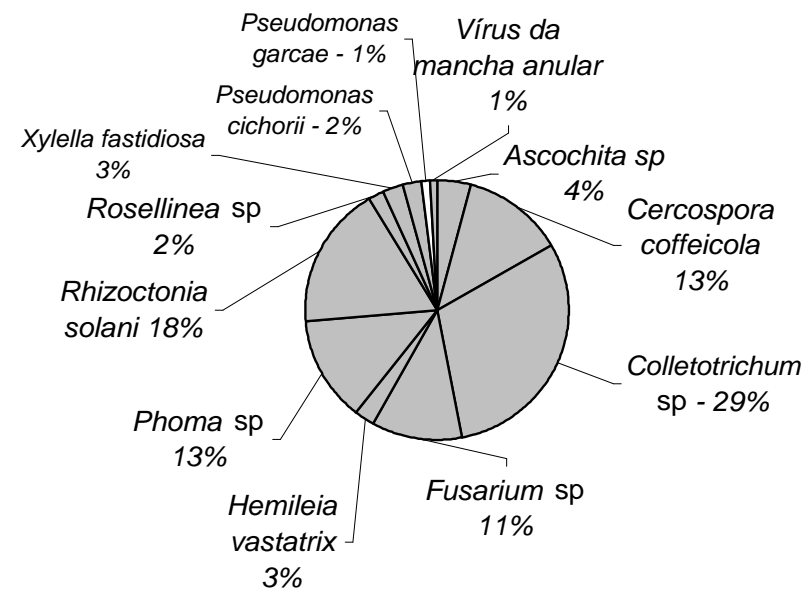

FIGURA 2 - Freqüência da ocorrência de agentes etiológicos bióticos, associados às amostras do cafeeiro recebidas na Clínica Fitossanitária do DFP/UFLA entre janeiro de 1990 e dezembro de 2001.

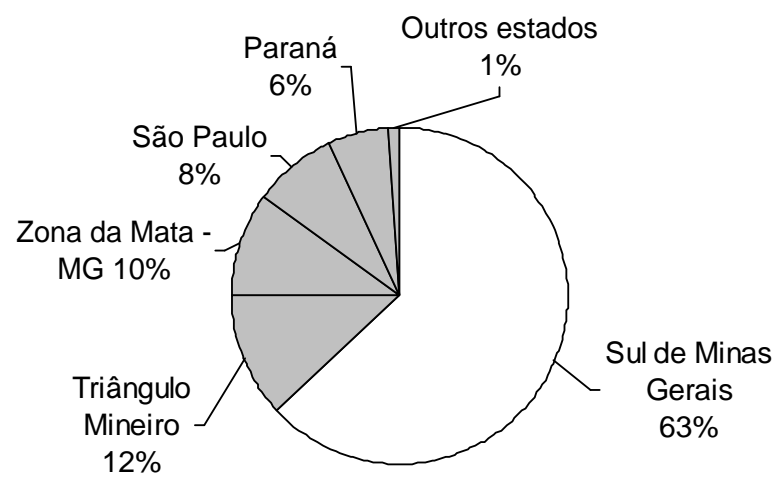

FIGURA 3 - Regiões de origem das amostras de café recebidas pela Clínica Fitossanitária do DFP/UFLA. 


\section{REFERENCIAS BIBLIOGRÁFICAS}

AGRIOS, G. N. Plant pathology. New York: Academic Press, 1997. 635 p.

ANUÁRIO ESTATÍSTICO DO CAFÉ 2000/2001. Rio de Janeiro: Coffee Business, 2000. Mídia Impressa.

BARNETT, H. L.; HUNTER, B. B. Illustrated genera of imperfect fungi. 4. ed. New York: Macmillan, 1987. $218 \mathrm{p}$.

GOMIDE, A. F. Levantamento de doenças bacterianas em hortaliças na região do cinturão verde de Belo Horizonte. 1989. 89 p. Dissertação (Mestrado em Fitossanidade) - Universidade Federal de Viçosa, Viçosa.

HAWKSWORTH, D. L.; KIRK, P. M.; SUTTON, B C.; PEGLER, D. N. Dictionary of the fungi. Wallingford: [s.n.], 1995. $616 \mathrm{p}$.

KADO, C. I.; HESKETT, M. G. Selective media for isolation of Agrobacterium, Corynebacterium, Erwinia Pseudomonas e Xanthomonas. Phytopathology, Saint Paul, v. 60, n. 6, p. 969-976, jun. 1970.

KIMATI, H.; AMORIM, L. BERGAMIM FILHO, A.; CAMARGO, L. E. A.; REZENDE, J. A. M. Manual de fitopatologia: doenças de plantas cultivadas. São Paulo: Agronômica Ceres, 1997. v. 2, 775 p.

KIRALLY, Z.; KLEMENT, Z.; SOLIMOSY, F. Methods in plant pathology. Budapeste: Akad Kiadó, 1974. $609 \mathrm{p}$.

PFENNING, L. H.; MARTINS, M. F. Espécies de $\boldsymbol{F} u$ sarium associadas ao cafeeiro na região sul de Minas Gerais. In: SIMPÓSIO DE PESQUISA DOS CAFÉS
DO BRASIL, 1., 2000, Poços de Caldas. Anais... Poços de Caldas: [s.n.], 2000. p. 283-286.

PONTE, J. J. Clínica de doenças de plantas. Fortaleza: Editora da Universidade Federal de Fortaleza, 1996. $872 \mathrm{p}$.

POZZA, E. A. Ocorrência de doenças da parte aérea de plantas na região de Lavras-MG. 1994. 97 p. Dissertação (Mestrado em Fitossanidade) - Universidade Federal de Lavras, Lavras.

POZZA, E. A.; SOUZA, P. E.; CASTRO, H. A.; POZZA, A. A. A. Frequiência da ocorrência de doenças de plantas na região de Lavras-MG. Ciência e Agrotecnologia, Lavras, v. 23, n. 4, p. 1002-1006, out./dez., 1999.

ROMEIRO, R. S. Bactérias fitopatogênicas. Viçosa: Imprensa Universitária, 1995. 283 p.

SALGADO, M.; PFENNING, L. Identificação e caracterização morfológica de espécies de Phoma do cafeeiro no Brasil. In: SIMPÓSIO DE PESQUISA DOS CAFÉS DO BRASIL, 1., 2000, Poços de Caldas. Anais... Poços de Caldas: [s.n.], 2000. p. 183-186.

ZAMBOLIN, L.; RIBEIRO DO VALE, F. X. Perdas ocasionadas pelas doenças de plantas. Informe Agropecuário, Belo Horizonte, v. 11, n. 131, p. 56-64, nov, 1985.

ZAMBOLIN, L.; RIBEIRO DO VALE, F. X.; PEREIRA, A. A.; CHAVES, G. M. Café (Coffea arabica $L$.), controle de doenças. In: RIBEIRO DO VALE, F. X.; ZAMBOLIN, L. (Ed.). Controle de doenças de plantas: grandes culturas. Viçosa: Imprensa Universitária, 1997. v. 2, p. 83-179. 